\title{
Desafios da equipe gestora no combate ao covid-19: Relato de experiência
}

\author{
Challenges of the management team in the fight Against covid-19: Experience report \\ Retos del equipo directivo em la lucha contra covid-19: Informe de experiencia
}

Recebido: 17/05/2021 | Revisado: 21/05/2021 | Aceito: 25/05/2021 | Publicado: 10/06/2021

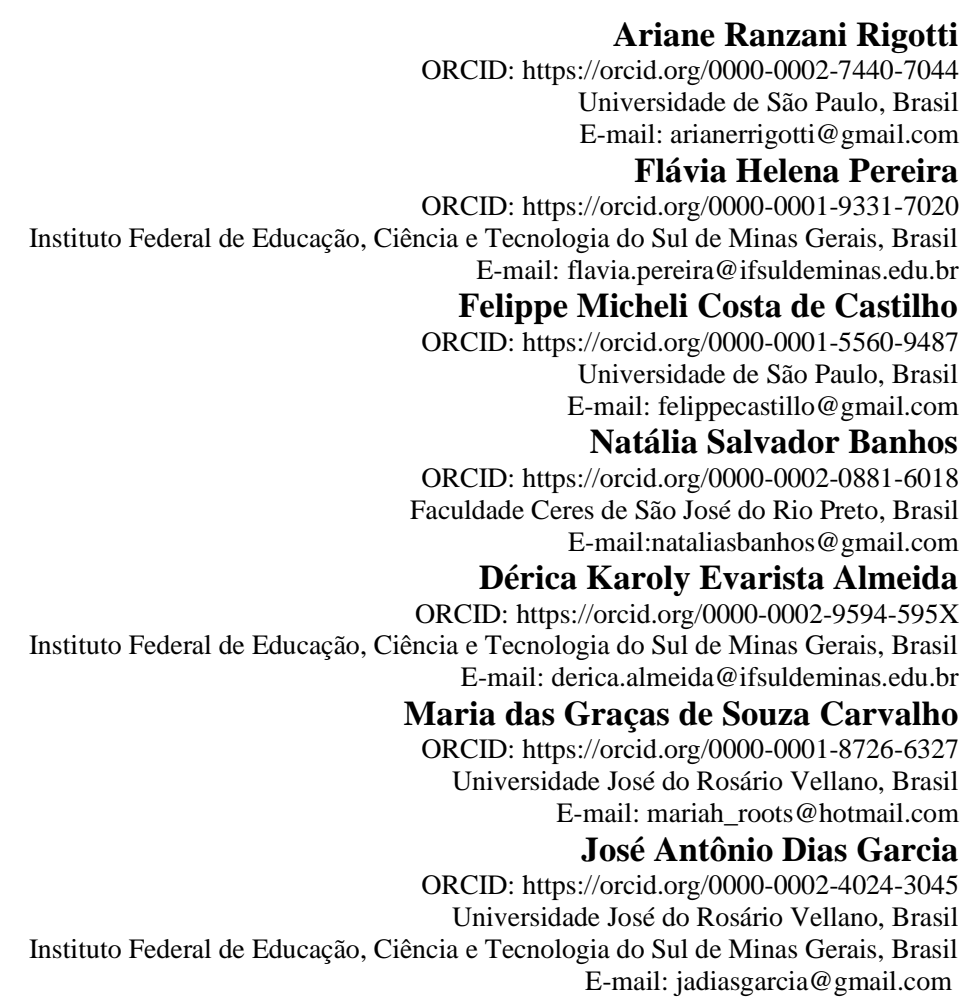

\section{Resumo}

Objetivo: Relatar os desafios enfrentados pela equipe gestora de um serviço hospitalar de nível secundário do interior do Estado de São Paulo, frente a pandemia COVID-19. Material e métodos: estudo descritivo, quantitativo e do tipo relato de experiência, que retrata os desafios enfrentados pela equipe gestora quanto ao treinamento dos profissionais da instituição e dimensionamento da equipe de enfermagem no período de fevereiro e março de 2020. Resultados: A equipe gestora precisou usar estratégias no treinamento dos profissionais da assistência à saúde e do departamento administrativo no uso e adesão dos EPIs, visto que havia o desconhecimento sobre a transmissão do vírus e a escassez de insumos de proteção individual no mercado. Quanto ao dimensionamento dos profissionais de enfermagem, a seleção dos colaboradores para compor a escala seguiu critérios considerados pré-definidos em conjunto com a gerência da instituição como: a qualificação no cuidado a pacientes críticos e o tempo de exposição ao vírus no ambiente de trabalho. Conclusão: A escassez de EPIs nos meses de fevereiro e março, e dos profissionais qualificados e a alta carga de trabalho da equipe de enfermagem foram desafios que os serviços de saúde enfrentaram desde o início da pandemia, assim foi necessário dispor de estratégias para o paciente e para a equipe de enfermagem, a fim de garantir o bem-estar a qualidade e a segurança de todos os envolvidos na assistência.

Palavras-chave: Infecções por coronavírus; Cultura; Dimensionamento de pessoal; Enfermagem; Segurança do paciente.

\begin{abstract}
Objective: To report the challenges faced by the management team of a secondary-level hospital service in the interior of the State of São Paulo, in the face of the COVID-19 pandemic. Material and methods: a descriptive, quantitative and experience report type study, which portrays the challenges faced by the management team regarding the training of the institution's professionals and the dimensioning of the nursing team in the period from February to March 2020. Results: The management team needed to use strategies in the training of health care professionals and the administrative department in the use and adherence of PPE, since there was a lack of knowledge about the transmission of the virus and the scarcity of individual protection supplies on the market. As for the dimensioning of nursing professionals, the selection of employees to compose the scale-followed criteria considered pre-defined in
\end{abstract}


conjunction with the institution's management, such as: the qualification in the care of critical patients and the time of exposure to the virus in the workplace. Conclusion: The scarcity of PPE in the months of February and March, and of qualified professionals and the high workload of the nursing team were challenges that health services faced since the beginning of the pandemic, so it was necessary to have strategies for the patient and for the nursing team, in order to guarantee the well-being, quality and safety of all those involved in the assistance.

Keywords: Coronavirus infections; Culture; Staff sizing; Nursing; Patient safety.

\section{Resumen}

Objetivo: Informar los desafíos que enfrenta el equipo directivo de un servicio hospitalario de nivel secundario en el interior del Estado de São Paulo, ante la pandemia COVID-19. Material y métodos: estudio descriptivo, cuantitativo y tipo informe de experiencia, que retrata los desafíos que enfrenta el equipo directivo en la formación de los profesionales de la institución y el dimensionamiento del equipo de enfermería entre febrero y marzo de 2020. Resultados: El equipo directivo necesitaba utilizar estrategias en capacitar a los profesionales de la salud y al departamento administrativo en el uso y adherencia de EPI, ya que existía un desconocimiento sobre la transmisión del virus y la escasez de insumos de protección individual en el mercado. En cuanto al dimensionamiento de los profesionales de enfermería, la selección de colaboradores para componer la escala siguió criterios considerados predefinidos en conjunto con la gestión de la institución, tales como: la calificación en la atención de pacientes críticos y el tiempo de exposición al virus en el ambiente de trabajo. Conclusión: La escasez de EPP en los meses de febrero y marzo, y de profesionales calificados y la alta carga de trabajo del equipo de enfermería fueron desafíos que enfrentaron los servicios de salud desde el inicio de la pandemia, por lo que fue necesario contar con estrategias para el paciente y para el equipo de enfermería, a fin de garantizar el bienestar, la calidad y la seguridad de todos los involucrados en la asistencia.

Palabras clave: Infecciones por coronavirus; Cultura; Dimensionamiento del personal; Enfermería; Seguridad del paciente.

\section{Introdução}

No final de 2019, o novo coronavírus, denominado Síndrome da Angústia Respiratória Severa - Coronavírus 2 (SARS-CoV-2), deu origem a uma epidemia respiratória aguda em Wuhan, na China. Em 11 de fevereiro de 2020 , a Organização Mundial da Saúde (OMS) denominou essa doença como Pandemia do Coronavírus-19, publicamente conhecida como COVID-19 devido ao aumento do número de casos fora da China e do número de países afetados pelo novo coronavírus (SARS-CoV-2) (Organização Mundial de Saúde, 2020).

Assim, a utilização correta dos equipamentos de proteção individual (EPIs) tornou-se fundamental, pois pesquisadores foram descobrindo que a transmissão do SARS-CoV-2 ocorria entre as pessoas por meio da auto inoculação do vírus em membranas mucosas (nariz, olhos ou boca) e do contato com superfícies contaminadas, o que alertou para a necessidade de adoção rápida e preventiva de medidas de proteção humana, a fim de dificultar a contaminação de pessoas (Oliveira, Lucas \& Iquiapaza, 2020).

Com isso, o uso de EPIs apropriados como máscaras, luvas, protetores de pés, protetores oculares, máscaras N95, aventais, óculos, protetores faciais e a higienização correta das mãos podem auxiliar na proteção contra microrganismos patogênicos, como o vírus em questão, durante a assistência realizada pelos profissionais de saúde aos pacientes com COVID19. É necessário garantir a proteção desses profissionais frente ao vírus com o propósito de não o transmitir nos serviços de saúde e em seus domicílios, evitando assim sua contaminação e adoecimento além de preservar o atendimento aos pacientes (Huang et al., 2020).

Os profissionais de saúde, em sua maioria a enfermagem, constituem um grupo de risco para a COVID-19, por estarem expostos a longo tempo diretamente aos pacientes infectados, o que faz com que recebam uma alta carga viral, e dentre outros problemas como o estresse psicológico e físico causado pelo cansaço, além da negligência e escassez com relação às medidas de proteção e cuidado à saúde desses profissionais (Teixeira et al., 2020).

Os enfermeiros, de um modo geral estão na linha de frente ao combate do COVID-19, sendo que os enfermeiros responsáveis pelos cuidados intensivos devem estar no epicentro dessa crise (Mitchell, 2020). No entanto, estamos testemunhando níveis sem precedentes no que tange o excesso de trabalho por parte de enfermeiros, profissionais da gerência 
ou os mais diretamente envolvidos na resposta à essa pandemia. Além do mais, enfermeiros de cuidados intensivos em todo o mundo estão passando por um período inadequado de descanso e recuperação, pouco apoio, assistência e considerações limitadas para sua saúde mental e bem-estar (News, 2020).

Existem várias consequências importantes da alta carga de trabalho de enfermagem, incluindo menor qualidade no atendimento e consequentemente maior chance de falhas relacionadas à segurança do paciente (Fagerström, Kinnunen \& Saarela, 2018; Ross, Rogers \& King, 2019). Além disso, a alta carga de trabalho de enfermagem afeta negativamente a satisfação no trabalho dos profissionais envolvidos e, como resultado, contribui para a alta rotatividade e a escassez de enfermagem (Carayon \& Gurses, 2008).

Assim, especificamente durante a pandemia da COVID-19, o tempo de trabalho que a enfermagem desempenha continua sendo um problema nos contextos atuais de assistência à saúde. Desta maneira, estudo demonstrou que pessoal e recursos adequados, apoio dos líderes administrativo e trabalho em equipe melhoram a segurança do paciente (Ross, Rogers \& King, 2019). Nesse cenário, os enfermeiros terão que demonstrar um novo nível de liderança. No entanto, eles também correm o risco de ficar traumatizados como resultado de suas experiências (Mitchell, 2020).

O objetivo deste trabalho é relatar os desafios enfrentados pela equipe gestora de um serviço hospitalar de nível secundário do interior do Estado de São Paulo, frente a pandemia COVID-19.

\section{Metodologia}

\section{Tipo de estudo}

Trata-se de um estudo quantitativo e do tipo relato de experiência. O relato de experiência é uma ferramenta da pesquisa descritiva que evidencia uma ação que aborda uma situação vivenciada no ambiente profissional de interesse da comunidade científica (Flick, 2013).

\section{Local do estudo}

A instituição, até o momento anterior à declaração da pandemia COVID-19, operava com 166 leitos de internação para pacientes adultos e um leito de hospital dia, além dos ambulatórios clínicos ecirúrgicos, sendo esses com atendimentos promovidos pelo Sistema Único de Saúde (SUS) e da Saúde Suplementar.

\section{Coleta de dados}

O período do relato da experiência foram os meses de fevereiro e março de 2020, nos quais se instalou, de fato, o atendimento aos pacientes com Síndrome do Desconforto Respiratório (SDRA) Agudo nas Unidades de Respiratório Agudo (URA) por meio de enfermaria, Unidade de Terapia Intensiva Adulto (UTI) e Pronto Atendimento (PA).

\section{Resultados}

O presente estudo utilizou como cenário um Hospital Escola do Interior do Estado de São Paulo de nível secundário, de média complexidade e referência na região. Antes da pandemia da COVID-19, o hospital possuía 10 leitos de Unidade de Terapia Intensiva Adulto (UTI), e 156 leitos de internação, sendo 23 destinados ao atendimento suplementar, e os demais ao atendimento do SUS. O hospital, além de setores de internação, prestava atendimento local e regional através de assistência ambulatorial de diversas especialidades clínicas e cirúrgicas.

A Instituição faz parte da composição das Unidades de Negócio de uma Fundação Filantrópica do município com atendimento populacional de 19 municípios conforme Distrito Regional de Saúde-DRS. O hospital tornou-se referência pelo fato da localização ser favorável em uma das entradas da cidade, além do espaço para ampliação estrutural. Com isso, a 
instituição recebeu cadastramento de mais 42 leitos para atendimento de pacientes com suspeita de COVID-19, sendo 20 leitos destinados a pacientes críticos com instabilidade hemodinâmica e 22 leitos de enfermaria.

Até o mês de fevereiro, referente ao dimensionamento da equipe de enfermagem, a instituição possuía 228 profissionais, sendo destes, 24 técnicos de enfermagem e cinco enfermeiros aptos para atuar no atendimento a pacientes críticos cujo atendimento é imediato e de suporte intensivo, quantidade adequada conforme a Resolução do COFEN n 543 de 2017 (Cofen, 2017), considerando a complexidade assistencial dos pacientes internados na instituição.

O planejamento das ações de combate à disseminação do COVID-19 teve início no mês de fevereiro de 2020, quando o Ministério da Saúde declarou Emergência de Saúde Pública de Importância Nacional (ESPIN), por meio da Portaria MS n 188 (Brasil, 2020a) e conforme Decreto n 7.616 de 17 de novembro de 2011 (Brasil, 2011). Logo então, foram iniciadas as transformações na estrutura, fluxo interno e externo de clientes, planejamento dos recursos humanos de enfermagem e aquisição de insumos para viabilizar o atendimento aos pacientes com COVID-19 e/ou com suspeita da doença.

As equipes gestoras da instituição, portanto, iniciaram encontros semanais, cujos objetivos das reuniões foram alinhar as decisões acerca dos recursos humanos necessários para o atendimento aos pacientes com COVID-19; planejar o orçamento destinado à aquisição de novos equipamentos e insumos necessários para o enfrentamento da pandemia; treinamentos frente ao uso dos EPIs, além da contratação de profissionais de enfermagem para atuarem na assistência a esses pacientes.

A instituição se tornou um Hospital de referência atendendo 19 municípios da região durante a pandemia da COVID19, por conseguinte as equipes de saúde precisaram se preparar para realizar o atendimento dos pacientes com COVID-19 e/ou com suspeita da doença, segundo os protocolos atualizados pela OMS e pelo Ministério da Saúde.

\section{Desafios quanto ao uso de EPIs pelos profissionais da saúde e administrativos}

O treinamento de todos os profissionais da instituição, quanto ao uso de EPIs, seguiu um cronograma intenso no decorrer dos meses de fevereiro e março de 2020. Foram inúmeros treinamentos oferecidos em forma de convocação a toda equipe de saúde da instituição, que se estendeu a todos os departamentos que compunha a força de trabalho da empresa, desde o setor administrativo, a princípio distante da assistência, até os componentes da "linha de frente".

A educação voltada para a higiene correta das mãos com água e sabão, álcool em gel 70\% e o uso racional da máscara foi o tema abordado de fundamental importância no início do processo de reestruturação do hospital e logo depois a temática referente ao uso correto da paramentação (máscaras, viseiras de proteção ocular, luvas e macacão).

Esta sistemática não evitou que alguns problemas pudessem surgir, mesmo porque a falta de informação adequada quanto a prevenção e transmissão do novo patógeno ainda era muito presente e gerava muitas dúvidas quanto a padronização dos EPIs e uso do álcool em gel 70\%. Diante desse cenário, o grande problema mundial referente a dificuldade na aquisição insumos e EPIs pelo aumento acelerado e não programado, passou a ser a nova realidade da instituição, visto que o uso irracional de máscaras e álcool em gel 70\% esteve muito presente no hospital.

A preocupação, o medo e a insegurança era tanta que os prestadores da assistência de saúde e administrativos iniciaram um consumo exagerado de máscaras e álcool em gel 70\% no primeiro momento, que só percebemos o nível de estabilização no consumo desordenado destes insumos após os treinamentos conduzidos pela Comissão de Controle de Infeção Hospitalar - CCIH, baseado em novos protocolos conduzidos pelo Ministério da Saúde - OMS.

Diante desse desafio foi necessário fortalecer os treinamentos otimizando o uso dos EPIs com segurança e com equilíbrio de consumo. Com isso, quando foi notado que este objetivo foi alcançado, os treinamentos foram direcionados particularmente a equipe de saúde, focando o uso de EPIs necessários para a prestação da assistência segura aos pacientes e à equipe. Nesse momento, todos os profissionais da saúde do hospital foram direcionados ao treinamento, mesmo porque não se sabia o quanto demandaria da assistência de enfermagem vinda da quantidade de atendimentos em nossa região e município. 
Com isso, poderia em um futuro breve, ter a necessidade de envolver toda a equipe de enfermagem na assistência a pacientes com COVID-19.

Foram diversos encontros educacionais destinados aos treinamentos para atingir 100\% de toda equipe de saúde, exceto férias e licença, que foram treinados logo após o retorno às atividades laborais. Conforme os EPIs específicos, como os macacões e viseiras, foram chegando na empresa, novos treinamentos educacionais foram elaborados de acordo com os modelos e marcas disponíveis no mercado, e inovadores treinamentos eram aplicados novamente a toda equipe assistencial.

\section{Desafios frente ao dimensionamento da equipe de enfermagem}

Agora, quando o assunto foi recursos humanos e mais propriamente o dimensionamento da equipe de enfermagem que neste momento faria parte da "linha de frente" da assistência, tivemos aflições, preocupações e muito medo.

Neste momento, começamos a perceber que pelo fato de não termos o curso da doença bem definido, patógeno pouco conhecido e protocolos institucional não delineados e concisos, a equipe de enfermagem passou a enfrentar um curso de insegurança, desespero e ansiedade impactando na escala mensal de revezamento da assistência de todo o hospital.

Ausências no trabalho por meio de atestados médicos passaram a fazer parte da rotina, porém o agravante era o tempo de ausência das atividades laborais de cada profissional.

Até o mês de março, tinha-se a ideia de que novas escalas de colaboradores teriam que ser confeccionadas, novos dimensionamentos não previstos teriam que ser planejados e mesmo com a quantidade sobressalente de leitos de internação, não teria contratação emergencial de profissionais da área de enfermagem. Com todas estas dificuldades, era necessária cautela para a seleção da equipe que "enfrentaria", este novo processo em curso.

Afinal, quais critérios seriam adotados para que não houvesse falha no processo do cuidado? E de que forma que se conseguiria promover a segurança do paciente e da equipe de enfermagem frente a assistência destes pacientes atendidos, visto que as ausências de mão-de-obra estavam claras e que seria mais um desafio que a gestão enfrentaria neste momento?

Estrutura física bem delineada e equipamentos tecnológicos chegando, os recursos humanos precisavam ser dimensionados, mesmo correndo o risco de algo planejado não ser almejado decorrente da taxa de atendimento aos pacientes com a COVID-19, com isso seria necessária reavaliação diária da escala de dimensionamento da equipe de enfermagem.

No primeiro momento, como não se sabia qual seria a característica clínica e patológica dos pacientes atendidos na instituição referente à gravidade da doença, além da quantidade de atendimentos dentro das unidades da instituição, logo sabendo que o hospital seria porta de entrada aos pacientes com desconforto respiratório, optou-se em dimensionar colaboradores de acordo com alguns critérios escolhido pela equipe de gestão de enfermagem.

A experiência em atendimento a pacientes críticos e o conhecimento teórico prático sobre urgência e emergência foram os pré-requisitos na seleção dos profissionais da enfermagem, porém outras premissas também foram avaliadas concomitantemente à qualificação dos colaboradores, pois poderiam interferir no sucesso e na segurança do paciente e dos profissionais da saúde.

Dessa forma, tempo de exposição a pacientes com SDRA foi outro aspecto integrado na seleção dos colaboradores. Julgou-se que seria necessário, a princípio, analisar se os envolvidos na assistência já prestavam atendimento ao mesmo perfil de pacientes em outra instituição de trabalho. Isso porque, muitos deles na área da enfermagem realizavam dupla jornada de trabalho e a maioria dos que atuavam em terapia intensiva desempenhavam a mesma função em outros serviços de saúde.

Esta preocupação foi embasada em trabalhos científicos que mostraram que na China, a contaminação dos trabalhadores foi favorecida pela proteção inadequada no início da epidemia, mas a exposição frequente e prolongada a pacientes potencialmente contaminados, a jornada de trabalho prolongada e intensa com tempo de descanso reduzido e a maior 
complexidade das tarefas de trabalho, levaram consideravelmente o aumento provável de infecção dos profissionais de saúde (Wang, Zhou \& Liu, 2020).

A princípio houve cautela em dimensionar os colaboradores não envolvidos no atendimento em outras instituições, mesmo porque além do risco biológico que estariam enfrentando, teriam também a exaustão psicológica que poderiam apresentar ao longo do tempo, como referem alguns trabalhos atuais, interferindo no sucesso do atendimento (Huang et al., 2020; Teixeira et al., 2020).

Documento científico afirma, portanto, que a quantidade de pessoas que apresentam impacto na saúde mental após um tempo de permanência longo no atendimento ao paciente com SDRA, é geralmente maior do que o número de pessoas que estão fisicamente feridas, e os efeitos na saúde mental podem durar muito mais tempo do que o esperado (Allsopp et al., 2019).

Experiência na área crítica, tempo mínimo de exposição ao provável patógeno e ao estresse emocional, foram os critérios que permearam a condição desfavorável para o dimensionamento da escala de enfermagem. Além disso, a empresa apresentava uma taxa de rotatividade de profissionais de enfermagem, turnover, não baixa o que fez contribuir para que o perfil dos colaboradores dificilmente enquadrasse nestes pré-requisitos, visto que a maioria dos profissionais de enfermagem da instituição eram recém formados e sem experiência na área da saúde.

O dimensionamento mensal da equipe de enfermagem, em primeiro instante, foi composto por enfermeiros e técnicos de enfermagem que tinham conhecimento referente ao atendimento a pacientes críticos e que não estavam envolvidos na assistência a estes pacientes em outros serviços de saúde por mais de 6 horas diurnas e 12 noturnas. Contou-se neste momento com o atendimento de profissionais qualificados e preparados para o atendimentos de todas as unidades de atendimento a pacientes COVID-19, sendo a enfermaria, UTI e PA. Assim, a escala precisava ser composta por 24 colaboradores da enfermagem, um enfermeiro e um técnico em cada área de atendimento, totalizando 6 profissionais em cada turno.

Com a estratificação dos setores em Unidade Respiratório Agudo (URA), pronto atendimento e enfermaria SUS/ atendimento suplementar, e diante de toda a dificuldade em manter os demais setores de internação vigentes de outras especialidades, além dos 10 leitos de Terapia Intensiva, cuja taxa de ocupação era 90\%, não conseguiu-se sustentar o dimensionamento envolvendo os critérios anteriormente estabelecidos e foi necessário inserir na composição das escalas da enfermaria os auxiliares de enfermagem.

Por conseguinte, a dificuldade de operar o dimensionamento seguindo os critérios idealizados foi evidenciada na confecção da primeira escala e, com isso logo de início, foram envolvidos muitos colaboradores que não se enquadravam no perfil desejado. Contudo, para suprir a necessidade de se ter uma equipe qualificada para o atendimento de pacientes com SDRA, criou-se plantões administrativos na área COVID-19. Além dos colaboradores escalados, a equipe contou com mais um supervisor da área de gestão de enfermagem no período de 24 horas, cujo objetivo era acompanhar todo o fluxo de atendimento e execução da assistência pela equipe de plantão, dando um suporte nos momentos de tomadas de decisões.

\section{Discussão}

Frente á este contexto, os maiores desafios enfrentados pela gestão de enfermagem e demais líderes organizacionais da instituição foram o dimensionamento da equipe de enfermagem para atuar no atendimento aos pacientes com SDRA e COVID-19 além de outros setores de internação da instituição, principalmente em UTI, e o treinamento da equipe de saúde quanto ao uso dos EPIs.

Considerando a emergência global promovida pela pandemia, o Brasil registrou falhas na proteção dos profissionais da saúde que colocou em risco inúmeros trabalhadores envolvidos na assistência direta. Esta pesquisa mostra que devido a escassez de EPIs e/ou à equívocos na paramentação ou desparamentação pelos profissionais envolvidos na "linha de frente", muitas vidas foram comprometidas (Agenzia Nazionale Stampa Associata, 2020; Wang, Zhou \& Liu, 2020). 
Diante dos problemas relacionados ao desabastecimento internacional e nacional dos EPIs, se fez necessário intensificar as recomendações sobre o uso racional e seguro dos EPI no transcorrer da cadeia assistencial de pessoas com suspeita ou confirmação de contaminação pelo novo coronavírus. O despreparo dos profissionais em lidar com estes equipamentos em suas rotinas e nos diferentes níveis assistenciais, provocou uma falsa sensação de proteção no ambiente de trabalho.

Logo, cabe aos serviços de saúde em todos os níveis de atenção, o treinamento dos profissionais (especialmente sobre técnicas de paramentação e desparamentação), a supervisão sobre uso dos EPIs, a manutenção e a reposição desses equipamentos conforme indicação do fabricante (Brasil, 2020b).

Além de profissionais preparados e treinados quanto ao uso de EPIs e adequado abastecimento desses insumos, profissionais qualificados também são importantes para reduzir os impactos negativos da pandemia, tanto aos profissionais da saúde quanto aos pacientes. Contudo, a escassez de pessoal qualificado para compor a escala de dimensionamento para atender os pacientes gravemente enfermos teve que ser superada com o envolvimento de outras categorias profissionais, dentre elas os auxiliares de enfermagem.

Este desafio também foi observado na China, pois havia cerca de 300 médicos e 1.000 enfermeiros de UTI na cidade de Wuhan, o que demandou migração de profissionais especializados de outras cidades chinesas para o centro da epidemia. É inegável, assim como ocorreu em Wuhan, que em cidades e hospitais com menos recursos estruturais, materiais e humanos, a taxa de mortalidade será maior pela falta de assistência adequada ao paciente (Xie et al., 2020).

Profissionais da equipe de enfermagem estão na linha de frente da luta contra o COVID-19 (Brasil, 2011). Por esse motivo, estão sendo testemunhados níveis sem precedentes de excesso de trabalho por parte das equipes de enfermagem, bem como de enfermeiros gestores e demais profissionais diretamente envolvidos na resposta à esta pandemia. Além do que, profissionais de enfermagem, em todo o mundo, estão relatando ausência de apoio físico e atenção à saúde mental, redução do tempo de descanso, escassez de equipamentos e colapso no Sistema de Assistência à Saúde (SAS), o que reflete diretamente no bem-estar dos mesmos (Jung et al., 2021; Gao, Barzel \& Barabási, 2016).

Várias são as consequências resultantes pela alta carga de trabalho da equipe de enfermagem como esgotamento físico e mental e desencadeamento de problemas psíquicos e emocionais, incluindo baixa qualidade do atendimento refletindo na segurança do paciente (Jung et al., 2021; Iflaifel et al., 2020). Este problema também afeta negativamente a satisfação no trabalho e, como resultado, contribui para a alta rotatividade e escassez de profissionais (Wang, Zhou \& Liu, 2020).

Assim, a carga de trabalho de enfermagem continua sendo um problema nos contextos atuais de assistência à saúde, especialmente durante a pandemia do COVID-19. A segurança é uma questão pertinente e de extrema importância, entretanto ainda é pouco lembrada na realidade dos profissionais da área da saúde, podendo refletir na condição de trabalho e na qualidade da assistência da equipe de enfermagem. A promoção da segurança da equipe de enfermagem dispende estratégias imprescindíveis para o bem-estar da equipe, garantindo indiretamente qualidade e segurança de todos envolvidos na assistência ao paciente.

\section{Considerações Finais}

A escassez de EPIs nos meses de fevereiro e março, de profissionais qualificados bem como a alta carga de trabalho da equipe de enfermagem foram desafios que os serviços de saúde enfrentaram desde o início da pandemia, assim foi necessário dispor de estratégias para o paciente e para equipe de enfermagem, a fim de garantir o bem-estar, a qualidade e a segurança de todos os envolvidos na assistência. Contudo, não é possível, até o presente momento, saber qual o impacto das mudança ocorridas na instituição durante a pandemia da COVID-19, pois ainda o hospital passa por processos de mudanças. 
Sugere-se, com isso a realização de pesquisas futuras sobre a temática, com o objetivo de medir esse impacto na qualidade do atendimento e na segurança dos profissionais e paciente atendidos no serviço de saúde.

\section{Referências}

Agenzia Nazionale Stampa Associata. (2020). Sociedade Cooperativa: Mais de dois mil médicos e enfermeiras contraíram vírus na Itália. Agência Italiana de Notícias. http://ansabrasil.com.br/brasil/noticias/italia/noticias/2020/03/16/mais-de-2-mil-medicos-e-enfermeiras-contrairam-virus-naitalia_010f1866-3b04402f-8e07-6461e179a2b9.html.

Allsopp, K., Brewin, C.R., Barrett, A., Williams, R., Hind, D., Chitsabesan, P., \& French, P. (2019). Responding to mental health needs after terror attacks. British Medical Journal, 366, 148282019.

Brasil. Ministério da Saúde. (2011). Decreto $n$. 7.616, de 17 de novembro de 2011. https://bvsms.saude.gov.br/bvs/saudelegis/gm/2 011/prt2952_14_12_2011.html

Brasil. Ministério da Saúde. (2020a). Portaria n. 188, de 3 de fevereiro de 2020. http://www.in.gov.br/en/web/dou/-/portaria-n-188-de-3-de-fevereiro-de-2020241408388

Brasil. Ministério da Saúde. (2020b). Recomendações de proteção aos trabalhadores dos serviços de saúde no atendimento de COVID-19 e outras síndromes gripais. https://portalarquivos.saude.gov.br/images/pdf/2020/April/16/01-recomendacoes-de-protecao.pdf

Carayon, P., Gurses, A.P. (2008). Nursing workload and patient safety - a human factors engineering perspective. In: Hughes RG, editor. Patient safety and quality: an evidence-based handbook for nurses. Rockville (MD): Agency for Healthcare Research and Quality.

Conselho Federal de Enfermagem - COFEN. (2017). Resolução COFEN 543/2017. http://www.cofen.gov.br/resolucao-cofen-5432017_51440.html

Fagerström, L., Kinnunen, M., \& Saarela, J. (2018). Nursing workload, patient safety incidents and mortality: an observational study from Finland. BMJ Open, $8(4), \mathrm{e} 016367$.

Flick, U. Introdução à metodologia de pesquisa: um guia para iniciantes. M. Lopes (Trad.). Penso, 2013. https://www.ets.ufpb.br/pdf/2013/2 \%20Metodos\%20quantitat\%20e\%20qualitat\%20-\%20IFES/Bauman,\%20Bourdieu,\%20Elias/Livros\%20de\%20Metodologia/Flick\%20-\%20Introdu cao\%20 \% $3 \%$ A $0 \% 20$ Metodologia\%20da\%20Pesquisa.pdf.

Gao J., Barzel, B., \& Barabási, A.L. (2016). Universal resilience patterns in complex networks. Nature, 530(7590), $307-12$.

Huang, L., Lin, G., Tang, L., Yu, L., \& Zhou, Z. (2020). Special atten-tion to nurses’ protection during the COVID-19 epi-demic. Critical Care, 24(1), 120.

Iflaifel, M., Lim, R.H., Ryan, K., \& Crowley, C. (2020). Resilient health care: a systematic review of conceptualisations, study methods and factors that develop resilience. BMC Health Services Research, 20(1), 324.

Jug, I.E.F.S., Kirby, E.E.F., Gregório, A.P.A., \& Gouvêa, M.V. (2021). Percepção acerca da Saúde Mental de uma equipe multiprofissional de uma emergência durante a pandemia de COVID-19. Research, Society and Development. https://rsdjournal.org/index.php/rsd/article/view/15164/13690

Mitchell, G. (2020). Covid-19 places critical nurses 'front and centre' as leaders Wethersfield. Nursing Times. https://www.nursingtimes.net/news/work force/covid-19-p laces-critical-care-nurses-front-and-centre-as-leaders-30-03-2020/.

News U. (2020). COVID-19 highlights nurses' vulnerability as backbone to health services worldwide: UN News. https://news.un.org/en/story/2020/04/1061232.

Oliveira, L.A., Lucas, T.C., \& Iquiapaza, R.A. (2020). What has the covid-19 pandemic taught us about adopting preventive measures? Texto \& contexto, 29, e20200106.

Organização Mundial de Saúde. WHO Director-General's opening remarks at the media briefing on COVID-19. Geneva: WHO. https://www.who.int/dg/speeches/detail/who-director-general-s-opening-remarks-at-the-media-briefing-on-covid-19---11-march-2020.

Ross, C., Rogers, C., \& King, C. (2019). Safety culture and an invisible nursing workload. Collegian, 1, 1-7.

Teixeira, C. F. S., Soares, C. T., Souza, E. A., Lisboa, E. S., Matos-Pinto, I. C., Andrade, L. R. \& Espiridião, M. A. (2020). A saúde dos profissionais de saúde no enfrentamento da pandemia de Covid- 19. Ciência \& Saúde Coletiva, 25(9), 3465-74

Wang, J., Zhou, M., \& Liu, F. (2020). Reasons for healthcare workers becoming infected with novel coronavirus disease 2019 (COVID-19) in China. Journal of Hospital Infection, 105(1), 100-1.

Xie, J., Tong, Z., Guan, X., Du, B., Qiu, H., \& Slutsky, A.S. (2020). Critical care crisis and some recommendations during the COVID-19 epidemic in China. Intensive Care Medicine, 46(5), 837-40. 